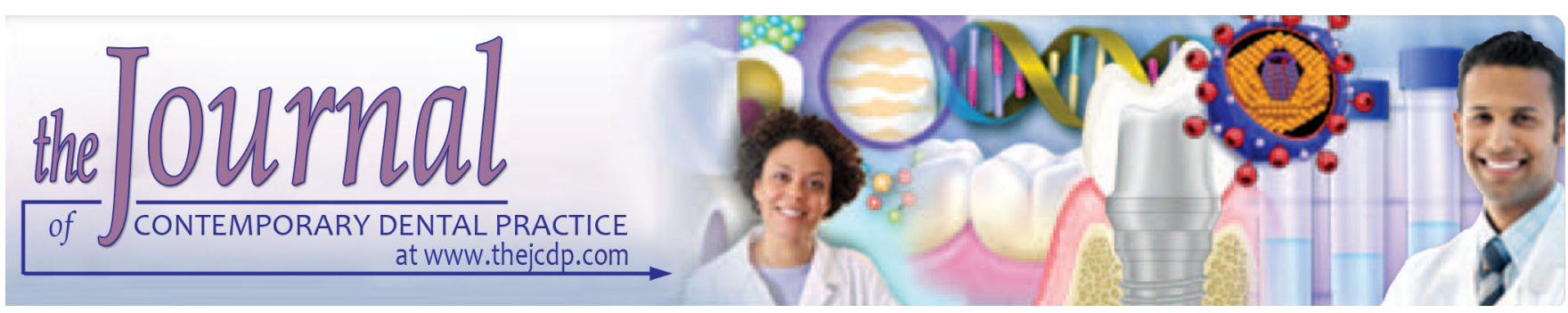

\title{
Human Mesiodistal Tooth Width Measurements and Comparison with Dental Cast in a Bangladeshi Population
}

\author{
${ }^{1}$ Mohammad Khursheed Alam, ${ }^{2}$ Fazal Shahid, ${ }^{3}$ Kathiravan Purmal, ${ }^{4}$ MA Sikder, ${ }^{5}$ Mohammed Saifuddin
}

\begin{abstract}
Aim: This analysis was aimed to determine the mesiodistal tooth width of human teeth and to compare with the measurements on plaster model in a Bangladeshi population.

Materials and methods: The samples of 2,892 teeth of Bangladeshi subjects were collected for this purpose. This article presents mesiodistal tooth width measurements made on all types of teeth and compares with the mesiodistal tooth width measurements of dental cast collected from Bangladeshi subjects between the ages of 18 and 24 years. The mesiodistal dimension was recorded, involving the maximum mesiodistal dimension of each tooth when measurement was rendered parallel to the occlusal and labial surfaces. Descriptive and comparative statistics were applied.
\end{abstract}

Results: The mean, standard deviation and 95\% confidence interval of mesiodistal tooth width measurements were determined and have been with the mesiodistal tooth width measurements of dental cast. Significant differences have been observed between mesiodistal tooth size of direct measurement on tooth (DMT) and measurement on plaster model (MPM) for the maxillary first molar $(p<0.001)$ and mandibular incisors to first premolar $(p<0.001)$.

Conclusion: These data should prove to be helpful to the practitioner for performing successful orthodontic treatment in Bangladeshi population.

\footnotetext{
1,2Department of Orthodontics, School of Dental Sciences Health Campus, Universiti Sains Malaysia, Kelantan, Malaysia

${ }^{3}$ Department of Oral and Maxillofacial Surgery, School of Dental Sciences, Health Campus, Universiti Sains Malaysia Kelantan, Malaysia

${ }^{4}$ Department of Orthodontics, Bangladesh Dental College Dhaka, Bangladesh

${ }^{5}$ Department of Orthodontics, Pioneer Dental College and Hospital, Dhaka, Bangladesh

Corresponding Author: Mohammad Khursheed Alam Senior Lecturer, Department of Orthodontics, School of Dental Sciences, Health Campus, Universiti Sains Malaysia Kotabharu-16150, Kelantan, Malaysia, Phone: +60142926987 e-mail: dralam@gmail.com
}

Clinical significance: Direct measurement of mesiodistal tooth width and individual variation of maxillary and mandibular permanent central incisor to first molar of the Bangladeshi individuals showed some distinguishable features, which will certainly help an orthodontist for diagnosis and treatment plan of an orthodontic case.

Keywords: Human tooth, Dental cast, Bangladeshi, Mesiodistal width.

How to cite this article: Alam MK, Shahid F, Purmal K, Sikder MA, Saifuddin M. Human Mesiodistal Tooth Width Measurements and Comparison with Dental Cast in a Bangladeshi Population. J Contemp Dent Pract 2015;16(4):299-303.

\section{Source of support: Nil}

Conflict of interest: None

\section{INTRODUCTION}

One of the most important essential criteria to diagnose an orthodontic case is to know the mesiodistal tooth width. ${ }^{1}$ Mesiodistal tooth width has an anthropological significance, because it provides valuable information on human evolution with its technological and dietary changes. ${ }^{1}$ A proper balance should exist between the mesiodistal tooth size of the maxillary and mandibular arches to ensure proper interdigitation, overbite, and overjet at the completion of orthodontic treatment. ${ }^{2,3}$ The size of the teeth is generally believed to be determined by genetic factors. ${ }^{4,5}$ Environmental factors, including neonatal factors, are also important in determining permanent tooth crown dimensions. ${ }^{6}$ On a clinical level, mesiodistal tooth width is correlated to the arch alignment and large teeth are associated with crowded dental arches. ${ }^{7}$ Differences in tooth size have been associated with different ethnic backgrounds and malocclusions. ${ }^{8}$ To date, no studies have been found in the literature to measure mesiodistal tooth width of Bangladeshi individuals using human teeth.

Most of the studies measured tooth size on plaster model. Is there a tendency of differences in tooth size 
between different samples? Unfortunately, there have been few reports on tooth size in a Bangladeshi population. ${ }^{9,10}$ Therefore, we previously investigated ${ }^{9}$ tooth size discrepancy in a Bangladeshi population and graphical overview of global tooth size ratios. The following results were obtained: (1) Gender differences in the anterior and overall ratios were not significant, (2) The following may be predictors of tooth size discrepancy: subjects with dental mid-line discrepancy (for the anterior ratio) and those with decreased overjet or decreased overbite (overall ratio), (3) A graphical presentation of the anterior ratios from the present study and using global data showed variations between populations and the overall ratios, albeit with some similarities. No study has been undertaken to compare between the direct measurement of human teeth and measurement on plaster model in a Bangladeshi population. Therefore, the aim of this study was to measure mesiodistal tooth width of human teeth and to compare with the measurement on dental cast.

\section{MATERIALS AND METHODS}

\section{Sample}

Six thousand maxillary and mandibular permanent central incisor to first molar tooth were collected from different clinic and hospital of Dhaka city. All teeth were preserved in hydrogen per oxide - water mix solution for 7 days for asepsis and were dried in sunlight. The criteria of accession were: (1) all teeth assessed to be morphologically normal, (2) absence of any decay, (3) absence of any interproximal restoration, (4) absence of any attrition, (5) absence of any erosion, (6) absence of any abrasion, (7) absence of any broken down crown, (8) absence of any crack, fracture. Finally, 1446 maxillary teeth and 1446 mandibular teeth, 241 teeth for each were selected for the measurement.

\section{Subjects}

Dental casts of 220 Bangladeshi individuals, comprising 95 males and 125 females (18 to 24 years, mean age $=20$ ). The records belonged to 100 subjects with class I normal occlusion (Class I NO). Sixty subjects with class I malocclusion (Class I MO), including those who showed crowding more than $5 \mathrm{~mm}$ and 30 subjects each with class II and III malocclusion. ${ }^{11}$ Dental cast was randomly chosen from dental students and orthodontic patients in the Orthodontic Department of the Bangladesh Dental College.

The inclusion criteria were the following: (1) subjects of confirmed Bangladeshi ethnic background, (2) existing and erupted permanent central incisors to the first permanent molar in each quadrant, (3) no previous orthodontic treatment, (4) all teeth assessed to be morphologically normal, and (5) absence of any decay, interproximal restorations, attrition, erosion, abrasion, broken down crowns, cracks and/or fractures.

\section{Tooth Size Measurements}

All measurements were taken by a single calibrated operator using a sliding calliper with vernier scale and a graded gauge (Mitutoyo, Japan). For each of the 2892 teeth measurement named 'direct measurement on tooth (DMT)' and for the cast measurement named 'measurement on plaster model (MPM). Measurements were carried out with a reading accuracy of $0.1 \mathrm{~mm}$. The mesiodistal dimension was recorded, involving the maximum mesiodistal dimension of each tooth when measurement was rendered parallel to the occlusal and labial surfaces.

\section{ETHICAL APPROVAL WAS OBTAINED FROM THE COLLEGE COMMITTEE, BANGLADESH DENTAL COLLEGE}

\section{Statistical Analysis}

A descriptive statistical analysis of the mesiodistal dimension of maxillary and mandibular permanent central incisor to first molar was accomplished. The individual data were summarized as ranges and mean values of these ratios. The data were reviewed for normal distribution. Variations were analyzed as standard deviations. Independent t-test was used to determine statistically significant differences of tooth size measurement between DMT and MPM with a probability level of 0.05 considered statistically significant. The reliability of the method was analyzed by the student t-test between examiners. The method deviation can thus be considered negligible. Twenty four teeth for each (a total of 288 teeth) and 40 pairs (ten pairs from each group) of dental casts were randomly selected and remeasured 1 month after the initial measurements.

Graphical flow chart of the study was shown in Flow Chart 1.

\section{RESULTS}

The agreement between the first and repeat measurement was acceptable in all the parameters analyzed, there were no statistically significant differences between the two sets of measurements. The average measure of intraclass coefficient correlation (ICC) were 0.91 - 0.97 and 0.92 - 0.97 for DMT and MPM respectively.

Table 1 summarizes the mean values, standard deviations, ranges, 95\% confidence interval and comparison p-value for the DMT and MPM of maxillary teeth. No 


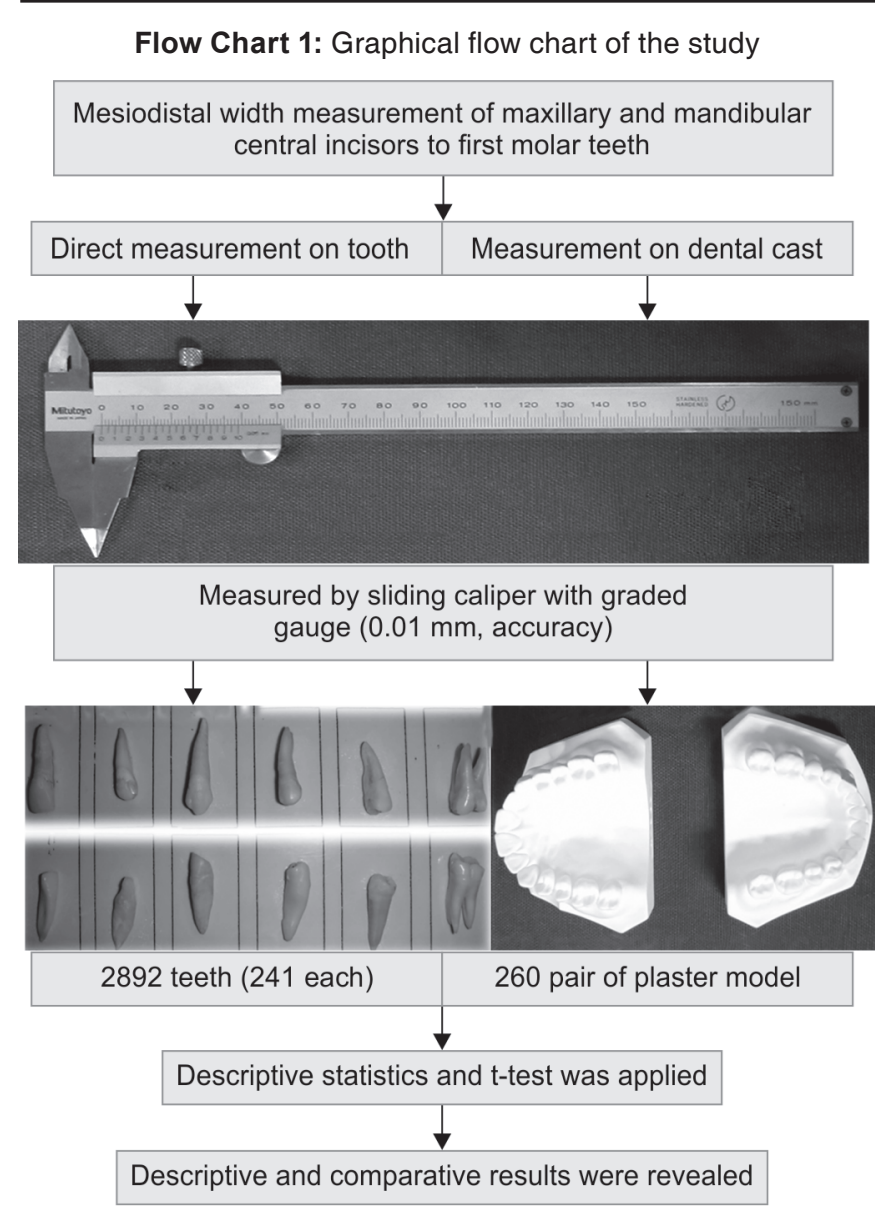

significant differences have been observed between mesiodistal tooth size measurements of DMT and MPM except for the first molar which showed highly significant differences $(\mathrm{p}<0.001)$.

Table 2 summarizes the mean values, standard deviations, ranges, $95 \%$ confidence interval and comparison $p$ value for the DMT and MPM of mandibular teeth. Significant differences have been observed between mesiodistal tooth size measurements of DMT and MPM incisors to first premolar $(\mathrm{p}<0.001)$ except for the first molar.

Graphical comparison between mesiodistal tooth size measurements of DMT and MPM of maxillary and mandibular teeth were shown in Graphs 1 and 2 respectively.

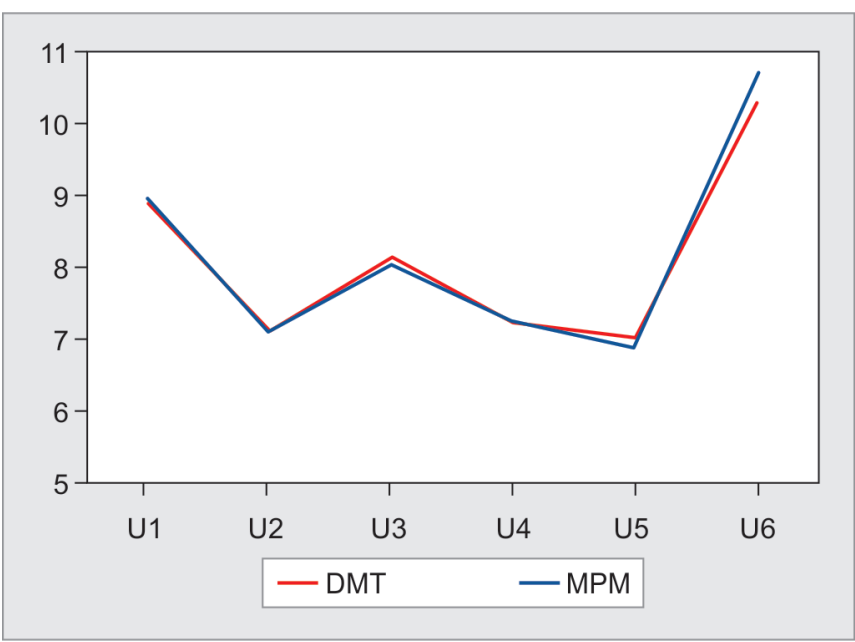

Graph 1: Comparison between mesiodistal tooth size measurements of DMT and MPM of maxillary teeth

\section{DISCUSSION}

Orthodontist should be aware of tooth size discrepancies before beginning orthodontic treatment. ${ }^{12}$ The mesiodistal tooth size of the maxillary and mandibular arches must relate to each other to obtain an optimal occlusion at the completion of the orthodontic treatment. ${ }^{2,13,14}$ If a patient has significant tooth size discrepancy, orthodontic alignment into optimal occlusion may not be possible. Many studies have been conducted to measure tooth size. $^{2,3,7,8,15,16}$ The results of the odontometric studies are useful not only in anthropologic research but for the practicing dentist too; since every known relationship or variation should be considered in daily patient care. ${ }^{16}$

Anthropometric studies reveal the variability between different races and between different ethnic groups within a race. For this reason, this information is useful not only for the determination of the evolutionary progress for a given population, but also for the evaluation of the biologic distance between races or ethnic groups, since some characteristics could serve as indicators of genetic differences between population. ${ }^{17}$ Clinical perceptions favored the idea that heredity played a major role in both craniofacial structure and tooth based malocclu-

Table 1: Descriptive and comparative results between mesiodistal tooth size measurements of DMT and MPM of maxillary teeth

\begin{tabular}{|c|c|c|c|c|c|c|c|}
\hline \multirow[b]{2}{*}{ Tooth variables } & \multicolumn{2}{|c|}{ Direct measurement on Tooth } & \multicolumn{2}{|c|}{ Measurement on plaster model } & \multicolumn{2}{|c|}{$95 \%$ confidence interval } & \multirow[b]{2}{*}{$p$-value } \\
\hline & Mean & $S D$ & Mean & $S D$ & Lower & Upper & \\
\hline U1 & 8.907 & 0.718 & 8.956 & 0.654 & -0.071 & 0.170 & 0.423 \\
\hline U2 & 7.098 & 0.755 & 7.109 & 0.619 & -0.110 & 0.132 & 0.859 \\
\hline U3 & 8.151 & 0.654 & 8.050 & 0.512 & -0.204 & 0.002 & 0.054 \\
\hline U4 & 7.203 & 0.550 & 7.240 & 0.627 & -0.067 & 0.141 & 0.483 \\
\hline U5 & 6.992 & 0.650 & 6.889 & 0.587 & -0.212 & 0.005 & 0.062 \\
\hline U6 & 10.301 & 0.680 & 10.704 & 0.694 & 0.282 & 0.524 & $0.000^{* * *}$ \\
\hline
\end{tabular}

p < 0.05: Significant; SD: Standard deviation; U1: Upper central incisor; U2: Upper lateral incisor; U3: Upper canine; U4: Upper first premolar; U5: Upper second premolar and U6: Upper first molar: ${ }^{* * *} \mathrm{p} \leq 0.001$ 
Table 2: Descriptive and comparative results between mesiodistal tooth size measurements of DMT and MPM of mandibular teeth

\begin{tabular}{|c|c|c|c|c|c|c|c|}
\hline \multirow[b]{2}{*}{ Tooth variables } & \multicolumn{2}{|c|}{ Direct measurement on Tooth } & \multicolumn{2}{|c|}{ Measurement on plaster model } & \multicolumn{2}{|c|}{ 95\% confidence interval } & \multirow[b]{2}{*}{$p$-value } \\
\hline & Mean & $S D$ & Mean & $S D$ & Lower & Upper & \\
\hline L1 & 5.941 & 0.513 & 5.767 & 0.472 & -0.260 & -0.087 & $0.000^{\star * *}$ \\
\hline L2 & 6.044 & 0.355 & 6.276 & 0.468 & 0.159 & 0.306 & $0.000^{* * *}$ \\
\hline L3 & 7.529 & 0.678 & 7.092 & 0.565 & -0.546 & -0.327 & $0.000^{\star * *}$ \\
\hline L4 & 7.129 & 0.676 & 7.373 & 0.489 & 0.142 & 0.347 & $0.000^{* * *}$ \\
\hline L5 & 7.017 & 0.726 & 7.267 & 0.583 & 0.135 & 0.365 & $0.000^{* * *}$ \\
\hline L6 & 11.210 & 0.657 & 11.296 & 0.795 & -0.042 & 0.215 & 0.186 \\
\hline
\end{tabular}

p <0.05: Significant; SD: Standard deviation; L1: Lower central incisor; L2: Lower lateral incisor; L3: Lower canine; L4: Lower first premolar; L5: Lower second premolar and L6: Lower first molar; ${ }^{* * *} \mathrm{p} \leq 0.001$

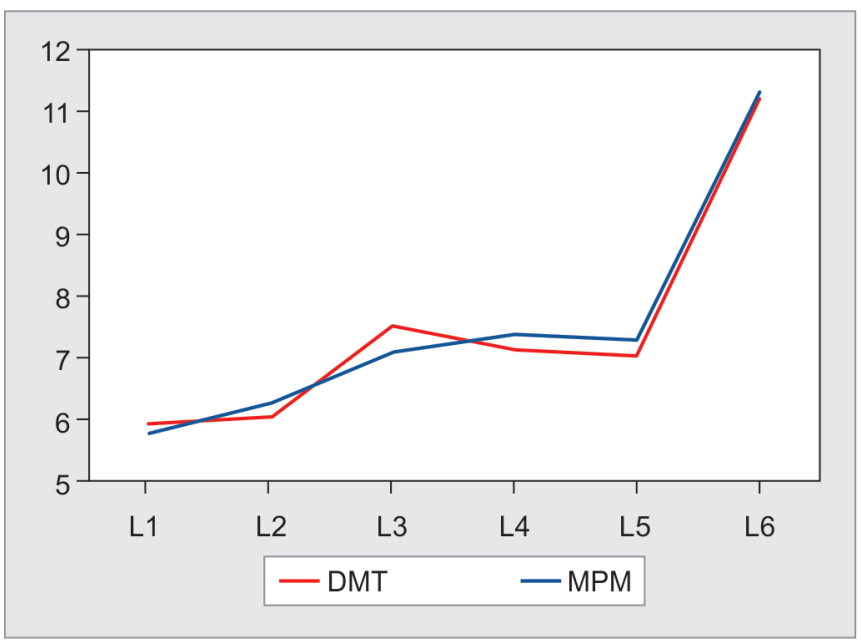

Graph 2: Comparison between mesiodistal tooth size measurements of DMT and MPM of mandibular teeth

sion. ${ }^{18}$ Tooth size is largely determined by heredity. Other factors which contribute to the variability of permanent tooth are race, sex, environment, etc. Environmental variation such as nutrition, disease or climate affect dentition during the prenatal period but seem to have little influence on normal dental variation. ${ }^{19}$

Our study do not support tooth size differences in different malocclusion groups. Crosby and Alexander, ${ }^{20}$ John and Donald, ${ }^{21}$ Nie and Lin, ${ }^{22}$ found no diffe-rence in tooth size in different malocclusion groups. As well as our findings also does not support gender diffe-rences which were considered in the studies of Smith et $\mathrm{al}^{23}$ and Uysal and Sari ${ }^{24}$ because we compared DMT and MPM in total population.

Tooth size mesiodistal width measured via plaster dental cast, ${ }^{25-27}$ digital dental models, ${ }^{28,29}$ and 3D CBCT acquisitions $^{12,30}$ for various dental investigation were ascertained valid. Current study compare between the direct measurement of human teeth and measurement on plaster model and found significant difference for the various variables. To avoid the unscrupulous consequence, measurement method difference in relation to patient treatment should be considered.

One of the most perplexing phenomena in orthodontics is the crowding and spacing before, as well as following, the completion of orthodontic treatment. ${ }^{15,16}$
By knowing the individual variation in the mesiodistal tooth width of maxillary permanent central incisor to first molar, an orthodontist even a dental surgeon can decide tooth size discrepancy in the maxillary arch which is very much essential to diagnose and to decide treatment plan of an orthodontic case. If a patient has significant tooth size discrepancy, orthodontic alignment into optimal occlusion may not be possible. 2,15,16 $^{\text {The results found }}$ from the two different types of Bangladeshi samples are quite discrete. The disparities may be due to precise measurement can be carried out in DMT rather than obstacle to penetrate the contact point while measurements in dental cast. The results of these odontometric studies are useful for the practicing dentist, since every known variation or relationship should be considered in daily patient care.

\section{CONCLUSION}

The results of this study showed some distinguishable features from direct measurement of mesiodistal tooth width and individual variation of maxillary and mandibular permanent central incisor to first molar of the Bangladeshi individuals which will certainly help an orthodontist for diagnosis and treatment plan of an orthodontic case.

\section{Clinical Significance}

Direct measurement of mesiodistal tooth width and individual variation of maxillary and mandibular permanent central incisor to first molar of the Bangladeshi individuals showed some distinguishable features, which will certainly help an orthodontist for diagnosis and treatment plan of an orthodontic case.

\section{REFERENCES}

1. Sarver DM, Proffit WR, Ackerman JL. Diagnosis and treatment planning in orthodontics. In: Graber TM, Vanarsdall RL Jr editors. Orthodontics, Current Principles and Techniques. 3rd ed. St Louis: Mosby 2000;3-15.

2. Tamimi TA, Hashim HA. Bolton tooth-size ratio revisited. World J Orthod 2005;6:289-295. 
3. Othman SA, Harradine NWT. Tooth-size Discrepancy and Bolton's Ratios: a literature review. J Orthod 2006;33:45-51.

4. Dempsey PJ, Townsend GC. Genetic and environmental contributions to variation in human tooth size. Heredity 2001;86:685-693.

5. Hughes T, Dempsey P, Richards L, Townsend G. Genetic analysis of deciduous tooth size in Australian twins. Arch Oral Biol 2000;45:997-1004.

6. Harila-kaera V, Heikkinen T, Avesalo L, Osborne RH. Permanent tooth crown dimensions in prematurely born children. Early Hum Dev 2001;62:131-147.

7. Kaji TS, Alam MK, Iida J. Chronological evaluation for frequency of crowding with choronological change of tooth size and jaw size. J Hokkaido Orthod Soc 2006;34:15-22.

8. Yonezu T, DDS, Warren JJ, Bishara SE, Steinbock KL, Comparison of tooth size and dental arch widths in contemporary Japanese and American preschool Children. World J Orthod 2001;2:356-360.

9. Alam MK, Hossain MR, Islam MA. Reliability of Bolton Tooth Size Discrepancies in Bangladeshi population. Int Med J 2013;20(2):229-231.

10. Alam MK, Iida J. Overjet, overbite and dental midline shift as predictors of tooth size discrepancy in a Bangladeshi population and a graphical overview of global tooth size ratios. Acta Odontologica Scandinavica 2013;71(6):1520-1531.

11. Angle FH. Classification of malocclusion. Dent Cosmos 1889; 41:248-264.

12. Alam MK, Shahid F, Kathiravan P, Ahmed B, Khamis, MF. Bolton tooth size ratio and its relation with arch widths, arch length and arch perimeter: a cone beam computed tomography (CBCT) study. Acta Odont Scand 2014;72:1047-1053.

13. Rahman MA, Nasima B, Farzana F, Alam MK. Analysis of Tooth Size Discrepancy (Bolton Ratio) among Orthodontic Patient at Combined Military Hospital (CMH), Dhaka. Int Med J 2014;21(1):38-40.

14. Alam MK, Hassan R, Mahmood Z, Haq ME. Determination and comparison of tooth size and tooth size ration in normal occlusion and different malocclusion groups. Int Med J 2013;20:462-465.

15. Bishara SE, Khadivi P, Jakobsen JR. Changes in tooth sizearch length relationships from the deciduous to the permanent dentition: a longitudinal study. Am J Orthod 1995;108:607-613.

16. Bishara SE, Jakobsen JR. Individual variation in tooth size/ arch length changes from the primary to permanent dentition. World J Orthod 2006;7:145-153.

17. Sofaer JA, Niswander JD, Maclean CJ, Workman PL. Population studies on southwestern Indian tribes. V. Tooth mor- phology as an indicator of biological distance. Am J Phys Anthropol 1972;37:357-365.

18. King L, Harris EF, Tolley EA. Heritability of cephalometric and occlusal variables as assessed from siblings with overt malocclusions. Am J Orthod Dentofac Orthop 1993;104: 121-131.

19. Bishara SE. Compensatory development interactions in the size of permanent teeth in three contemporary populations. Angle Orthod 1989;2:107-112.

20. Crosby DR, Alexander CG. The occurrence of tooth size discrepancies among different malocclusion groups. Am J Orthod Dentofacial Orthop 1989;95:457-461.

21. John M, Donald JB. An investigation of tooth size in Northern Irish people with bimaxillary dental protrusion. Eur J Orthodont 1996;18:617-621.

22. Nie Q, Lin J. Comparison of intermaxillary tooth size discrepancies among different malocclusion groups. Am J Orthod Dentofac Orthop 1999;116:539-544.

23. Smith SS, Buschang PH, Watanabe E. Interarch tooth size relationships of 3 populations: 'does Bolton's analysis apply?' Am J Orthod Dentofacial Orthop 2000;117:169-174.

24. Uysal T, Sarı Z. Intermaxillary tooth size discrepancy and mesiodistal crown dimensions for a Turkish population. Am J Orthod Dentofac Orthop 2005;128:226-230.

25. Alam MK, Noor MIM, Tajuddin MF, Basri R, Purmal K, Rahman SA. Variation in tooth size and arch dimension in Malaysian Chinese subject with torus palatinus. Int Med J 2014;21:181-183.

26. Alam MK, Noor MIM, Tajuddin MF, Basri R, Purmal K, Rahman SA. Comparison of variation in tooth size and arch dimension in malaysian malay and malaysian chinese subject with torus palatinus. Int Med J 2014;21:184-187.

27. Noor MIM, Tajuddin MF, Alam MK, Basri R, Purmal K, Rahman SA. Variation in tooth size and arch dimension in Malaysian Malay subject with torus palatinus. Int Med J 2014;21:193-195.

28. Alam MK, Shahid F, Nowrin SA. Digital impression model (DIM) a new, quick, simple, reliable and cost effective procedure. Bangladesh J Med Sci 2014;13:231-232.

29. Shahid F, Alam MK, Khamis MF, Muraoka R, Nakano K, Okafuji N. Validity and reliability of digital model measurements: a digital stereomicroscopic study. J Hard Tissue Biol 2014;23:439-444.

30. Alam MK, Shahid F, Purmal K, Ahmad B, Khamis MF. Tooth size and dental arch dimension measurement through cone beam computed tomography: effect of age and gender. Res J Rec Sci 2014;3:85-94. 